\title{
Enhancing public awareness and promoting co- responsibility for marine litter in Europe: the challenge of MARLISCO
}

Joana M. Veigaa, Thomais Vlachogiannib, Sabine Pahlc, Richard Thompsond, Kathrin Kopkee, Thomas K. Doylef, Bonny L. Hartleyc, Thomas Maes', Demetra L. Orthodoxou' ${ }^{\mathrm{h}}$, Xenia I. Loizidou $^{\text {h }}$ and Iro Alampei ${ }^{b}$

${ }^{\text {a }}$ Coastal \& Marine Union (EUCC)

P.O. Box 11232, 2301 EE Leiden, the Netherlands

Tel.: + 31715122900

Joana Mira Veiga: j.veiga@eucc.net

${ }^{b}$ Mediterranean Information Office for Environment, Culture and Sustainable Development (MIO-ECSDE)

12, Kyrristou str., 10556 Athens, Greece

Tel.: +30210 3247490, Fax: +302103317127

Thomais Vlachogianni: vlachogianni@mio-ecsde.org

Iro Alampei: alampei@mio-ecsde.org

' Plymouth University, United Kingdom

School of Psychology, University of Plymouth,

Drake Circus, Plymouth, PL4 8AA, United Kingdom

Tel.:+ 441752584651 , Fax: +44 1752584605

Sabine Pahl: sabine.pahl@plymouth.ac.uk

Bonny Hartley: bonny.hartley@gmail.com 
d Plymouth University, United Kingdom

School of Marine Science and Engineering, University of Plymouth,

Drake Circus, Plymouth, PL4 8AA, United Kingdom

Tel.:+ 441752 584651, Fax: +441752 584605

Richard Thompson: r.c.thompson@plymouth.ac.uk

e MaREI Centre, Environmental Research Institute,

Beaufort Building, University College Cork,

Haulbowline Road, Ringaskiddy

Co. Cork, Ireland

Tel.: +353214864300

Kathrin Kopke: k.kopke@ucc.ie

f School of Natural Sciences (Zoology), Martin Ryan Institute

National University of Ireland Galway

University Road, Galway

Ireland

Tel.: +35391493744

Tom Doyle: tom.doyle@nuigalway.ie

${ }^{g}$ Centre for Environment, Fisheries \& Aquaculture (Cefas)

Pakefield Road, NR33 OHT, Lowestoft, United Kingdom

Tel: +44 1502 562244, Fax +44 1502513865

Thomas Maes: thomas.maes@cefas.co.uk

${ }^{h}$ ISOTECH Ltd Environmental Research and Consultancy

1 Kalliopis Str. \& Larnakos Ave., Apt. 401,2102 Aglantzia, Nicosia, Cyprus

Tel: + 35722452727 , Fax: + 35722458486

Demetra L. Orthodoxou:project@isotech.com.cy

Xenia I. Loizidou: xenia@isotech.com.cy 


\begin{abstract}
Marine litter is a pervasive and complex societal problem but has no simple solution. Inadequate practices at all levels of production-use-disposal contribute to accumulation of waste in land and sea. Enhanced societal awareness but also co-responsibility across different sectors and improved interactions between stakeholders is necessary.

MARLISCO was a European initiative, which developed and implemented activities across 15 countries. It worked towards raising societal awareness and engagement on marine litter, through a combination of approaches: public exhibitions in over 80 locations; a video competition involving 2100 students; a legacy of educational and decision-supporting tools. 12 national participatory events designed to facilitate dialogue on solutions brought together 1500 stakeholders and revealed support for cross-cutting, preventing measures. Evaluation during implementation shows these activities are effective in improving individuals' perceptions about the problem but also commitment in being part of the solution. This paper summarises MARLISCO approach and highlights a selection of outcomes.
\end{abstract}

Keywords: marine litter; waste management; MSFD; awareness raising; stakeholder engagement; 


\section{Introduction}

Marine litter is defined as any manufactured item or material deliberately discarded or unintentionally lost into the sea or coastline, including those transported into the marine environment from land by rivers, drainage or sewage systems and wind (Galgani et al., 2010). While it corresponds to a very wide range of items with different origin, usage and composition, plastics consistently rank as the most abundant types of marine debris on a global scale (STAP, 2011; Galgani et al., 2015). European Regional Sea Conventions reports show that plastics account for $50-80 \%$ of litter items found on beaches (OSPAR, 2009; HELCOM, 2009; UNEP/MAP MEDPOL, 2008).

Marine litter is a growing cross-sectoral global challenge that does not recognise geographic or political boundaries. Its negative ecological and socioeconomic impacts pose severe threats to the marine and coastal environment and human livelihoods, affecting habitats, species and ecosystems services; human health and safety; vital economic sectors such as fisheries, tourism and navigation (Kershaw et al. 2011; Mouat et al. 2010; CBD, 2012; STAP 2011; Thompson et al. 2009; UNEP, 2009). Particularly after the RIO+20 Summit (UN, 2012), marine litter is recognized as one of the major pollution problems worldwide. Apart from the primary/direct impacts of marine litter on marine wildlife resulting from entanglement and ingestion, there is concern about secondary impacts such as bio-accumulation and bio-magnification of toxic substance either released from plastic items (e.g. PBDEs, phthalates, Bisphenol A) or adsorbed and accumulated on plastic particles (e.g. POPs, PAHs) (Oehlmann et al., 2009; Rochman \& Browne 2013; Teuten et al., 2009).

The production of plastics has increased substantially over the last 60 years from around 0.5 million tonnes in 1950 to over 260 million tonnes and in Europe alone the plastics industry has a turnover of 300 million euros (Thompson et al., 2009). Plastics are not only ubiquitous in our daily lives but they are now found throughout the marine and coastal environment, from the poles to the Equator, from shorelines and the sea surface to the sea floor (Galgani et al., 2015; Thompson et al., 2009; Eriksen et al., 2014). Inadequate solid waste management, inappropriate waste disposal by consumers at large and discharge of inappropriately treated/untreated waste water can all lead to litter entering the sea but there is also direct input in the marine environment from maritime activities, coastal tourism and recreation (STAP, 2011; Barnes et al., 2009).

From a life-cycle perspective, the linear use of resources from production to a short-lived single-use stage to disposal is a central underlying cause of the accumulation of waste in land and the sea (Barnes et al., 2009; Thompson et al. 2009). Recognition that marine litter is not merely a waste management issue is 
fundamental to addressing the underlying causes of this problem. As such, addressing it through a complete life-cycle approach is one of the potential testing grounds for the green economy and the circular economy (Braungart $\&$ McDonough, 2002; European Commission, 2014). The STAP solutions-based framework (STAP, 2011) indicates the need for relevant stakeholder dialogue and linkages between industry, society and policy in order to achieve solutions. Furthermore, the combination of strategies outlined includes the 3 R's - reduce, reuse, recycle which are widely advocated to reduce the quantities of waste and introduce two more: - redesign and recover (STAP, 2011).

In recent years, marine litter has received major attention from the European Commission and the EU Member States, as it represents one of the 11 Descriptors within the Marine Strategy Framework Directive (MSFD - European Directive 2008/56/EC), in relation to which monitoring programmes and a set of measures need to be implemented to reach or maintain "Good Environmental Status" by 2020. Furthermore, considerable work is ongoing at the European Regional Seas Conventions with regards to the development and implementation of Regional Action Plans on Marine Litter. Several other funding schemes have been made available to improve the understanding of associated processes and implications of marine litter but also to promote and facilitate the coordination of efforts of the countries towards harmonized monitoring approaches (Galgani et al., 2013) and effective solutions.

MARLISCO - Marine Litter in Europe's Seas: Social Awareness and Coresponsibility was a European project (2012-2015) assembling a multidisciplinary group of 20 entities, which joined forces to tackle the issue of marine litter at the science-society interface, by implementing engagement activities in 15 coastal countries, in the four European Regional Seas. This paper aims at showcasing the mechanisms set up and the tools developed within this project, while providing indications of their effectiveness in increasing awareness and empowering the targeted audience. Some key outcomes, challenges and lessons learned will be highlighted and discussed, demonstrating the importance and the continuous need for these consistent and collective efforts, with regards to addressing such a transversal challenge as marine litter.

\section{The challenge and strategic approach of MARLISCO}

At present, problems associated with marine litter are exacerbated by a combination of: lack of awareness within society on the extent of the problem; lack of awareness of potential solutions; and lack of communication and articulation mechanisms between the different stakeholders. MARLISCO aimed to raise public awareness, trigger a sense of co-responsibility within different sectors and facilitate dialogue between the different actors on both the problems and the potential solutions related to marine litter. The project 
focused on the development, implementation and evaluation of mechanisms to: i) communicate a complex problem in its environmental and social dimensions, encouraging society to gain a deepened understanding of the issue of marine litter ii) address the disconnection between the problem and the responsibility of individual behaviour and sectorial practices iii) actively engage and bring together key stakeholders to define a more sustainable collective vision, constructively identify viable solutions and eventually pave the way for concerted actions to address this complex issue.

MARLISCO incorporated a set of activities including a scoping study on the characteristics of marine litter and related policies in each European Regional Sea; a collection of best practices from all partner countries; an assessment of the prevailing perceptions and attitudes of different stakeholders regarding marine litter; national fora in 12 partner countries (Figure 1), involving key stakeholders and the wider public; a European video contest for school students; a wealth of awareness raising and educational activities and innovative tools designed for the younger generation; an exhibition replicated in different national languages.

A key aspect of MARLISCO was the wide geographic spread but also sectorial coverage of its partnership - the consortium was composed of a diverse range of entities, from regional and local authorities, research institutes and academia, environmental associations, industries and multimedia companies. 15 of these organisations were responsible for implementing a set of national activities in their countries and therefore MARLISCO covered 14 EU Member States and Turkey, with representation in each of the four European Regional Seas: NorthEast Atlantic, Baltic, Mediterranean and Black Sea. As with many multifaceted societal problems, effective solutions require the joint action of the general public, of industry and policy. The project benefited from the inclusion of three associations of the plastic industry, representing plastic producers, converters and recyclers throughout Europe.

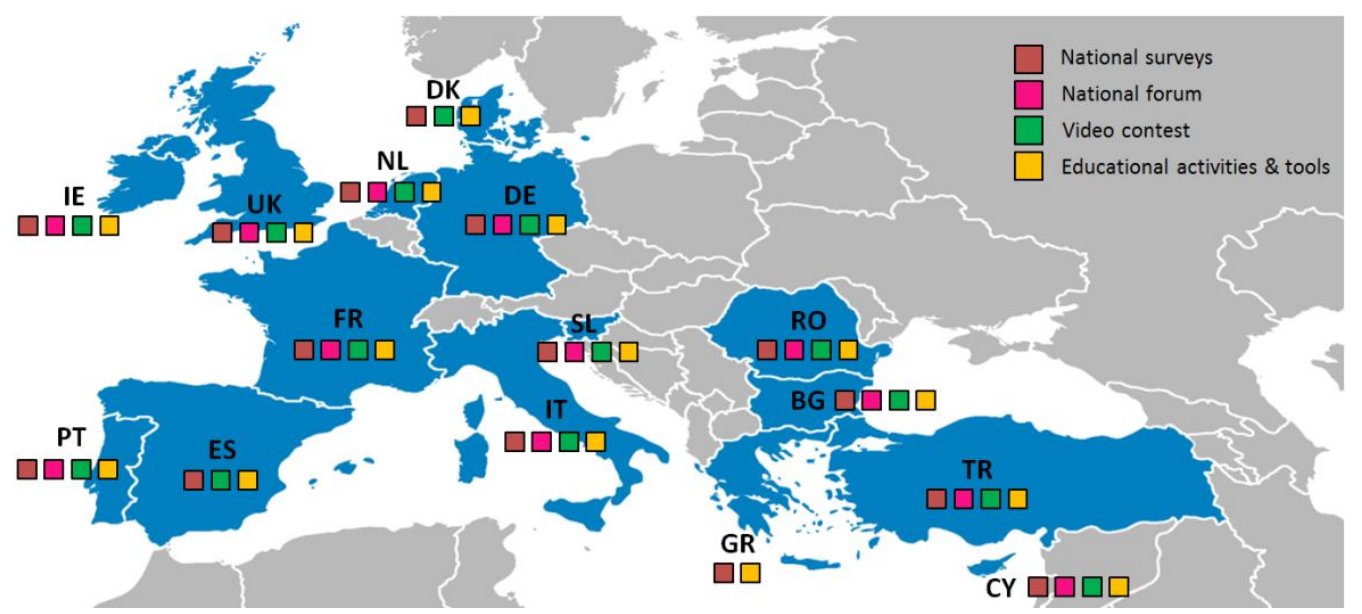

Figure 1. Geographical coverage of MARLISCO partners and implemented activities 


\section{Main lines of action and achieved results}

\subsection{Formulating clear messages based on sound scientific evidence and findings}

There are still uncertainties and crucial knowledge gaps related to marine litter, specifically on amounts, their fate in the marine environment and their toxicological impacts (e.g. Browne et al., 2015). In such a context, there is a potential for misconceptions to arise, within media and society. It is therefore imperative to base messages on clear, evidence-based information when informing, engaging and empowering stakeholders, including the general public.

With this in mind, one of the initial activities of MARLISCO was to set a clear picture regarding what is known on the topic in each of the European regional seas. This included a scoping study on amounts, sources, distribution and impacts of marine litter (Kershaw et al., 2013a); and an overview of the legislative frameworks at international and regional level, e.g. Europe and Regional Sea Conventions, that directly or indirectly deal with litter found in the sea (Kershaw et al., 2013b). Furthermore, Kershaw et al (2013a) address basic 'Facts \& Figures' and clarify popular misconceptions on the issue, namely the so-called "islands of trash" in the Pacific or biodegradable plastics as a panacea for plastic pollution. Apart from synthesizing and consolidating existing knowledge to underpin MARLISCO's actions, this activity contributed to the project's general aim of a better understanding of the science-society nexus and the conditions for translating research-based knowledge into action, thus special emphasis was given to the identification of key actors, specificities and/or priorities within each of the countries involved.

\subsection{Perceptions, attitudes and commitment within European society}

It is essential to understand how people perceive the problem of marine litter when attempting to facilitate changes in attitudes and behaviour, yet surprisingly little is known about this. Two specific objectives of MARLISCO were i) to assess societal perceptions about marine litter and ii) to evaluate the impact of the project's educational and engagement activities with a range of stakeholder groups. To achieve this, a number of social surveys suitable for implementing with a range of participants, including children, general public and educators across Europe were designed.

i) Assessing societal perceptions about marine litter. MARLISCO has conducted an extensive European-wide survey of societal awareness and perceptions about marine litter. More specifically, the study sought to examine individuals' understanding about the quantity, location, causes and consequences of marine 
litter, perceived risk and responsibility, and behavioural intentions to engage in solutions. The survey was launched in 15 coastal countries (Fig. 1) and a total of more than 3500 responses were collected from targeted key sectors, including production industry, retailers, coastal and marine industry, waste management, government and policy makers, environmental organisations, the media, education sector and the general public. Responses provided a better insight of the barriers and opportunities in stakeholders' understanding of the issue and engagement in effective solutions. Initial analysis shows that people notice litter on most visits to the coast, are concerned about the issue and recognize that it does not only affect coastal communities but is a problem of the society as a whole. However, the need for raising awareness is also highlighted, as respondents seem inclined to regard the problem more as a future threat rather than a present one and misperceive the composition of marine litter, for example by underestimating the percentage of plastic that comprises it (Hartley et al., 2013).

ii) Evaluating the impact of MARLISCO's activities. Based on principles and methods from the social sciences, surveys were applied to measure the impact of the key educational and engagement activities implemented throughout the project. The evaluations assessed whether and how each activity changed people's understanding, attitudes and behaviour. The National Fora (section 3.4) have been evaluated with a short survey that participants completed before and after they've attended the event, designed to assess participants' level of concern, feelings of efficacy, responsibility and motivation, perceptions about solutions and intentions to engage in actions to prevent and reduce marine litter. A similar 'before-after' method was implemented to determine the impact that the Video Competition (section 3.5) had on youngsters' understanding of the causes and consequences of marine litter and their level of action. An additional survey has been developed to evaluate whether MARLISCO's elearning course increased educators' understanding of the issue and their confidence, motivation and intentions to integrate the topic into their formal or informal teaching practice. Finally, the evaluation developed for the National Exhibitions (section 3.6) provided a snapshot of what visitors recall as the most memorable aspect of the exhibits, recorded their level of concern about marine litter and the number of action pledges they would be prepared to make. Details and discussion of results of these assessments are provided in Hartley et al (2015a) and the overall impact is briefly presented in sections where the evaluated activities are addressed.

These evaluations demonstrate the potential for engaging different spheres of society, in raising awareness about marine litter, increasing understanding and encouraging commitment to contribute to solutions. It is therefore crucial that outreach and educational activities are evaluated in order to gauge their success and provide an evidence base for future practice. 


\subsection{Inspiring action through concrete examples}

As in other complex environmental issues, the problem is not always related to a lack of knowledge but rather to the context for using this knowledge and incentives to actually turn it into action (Naustdalslid, 2011). To demonstrate that it is possible to move towards better practices and effective actions in relation to marine litter, while fostering a sense of co-responsibility across different sectors, MARLISCO identified and analysed a series of examples of initiatives and policies from all the involved countries. A total of 72 best practices have been described and made publically available through a database within the MARLISCO web-portal (www.marlisco.eu). These are implemented by a range of stakeholder groups (local authorities, public bodies, fishermen and their associations, NGOs), they can be regulatory measures or voluntary initiatives, and address marine litter in different phases of its lifecycle from prevention of waste to removal of litter from the sea.

A successful example of an economic market-based instrument enforced by regulation is the tax on plastic shopping bags. In Ireland, the plastic bag levy was introduced in March 2002 and reduced the number of bags entering the consumption stream by over $90 \%$ (Convery et al., 2007). Charged initially at $€ 0.15$ per bag and after 2007 at $€ 0.22$, it led to a dramatic change in consumer behaviour overnight, from a pre-tax average of 328 to 14 bags/inhabitant/year in 2012 (Department of the Environment, Community and Local Government, 2014). Proceeds of the levy are paid into an Environment Fund, with annual revenues in the order of $€ 12-14$ million. This Fund is operated by the Ministry of the Environment and used to support and promote a variety of environmental programmes (Convery et al., 2007). Most importantly however, the levy was associated with positive attitudes in main stakeholders (the public and the retail industry), with the majority of them supporting its implementation (see also Poortinga et al., 2013 for Wales, UK).

Another particularly successful practice is the voluntary scheme "Responsible Snack Bars" in Spain. This initiative was launched in 2012 by the Biodiversity Foundation of the Ministry of Agriculture, Food and Environment and aimed at encouraging environmentally friendly performance by beach snack bars ("chiringuitos"), through their adoption of a "code of conduct" based on good environmental practices. This was promoted by an attribution of awards to those facilities that presented exemplary activities or ideas. During the first edition of the programme 526 snack bars, from 7 regions in Spain, joined the initiative and during the second edition this number doubled.

A range of initiatives have been implemented throughout Europe involving the general public in taking action against marine litter or to be actively engaged in waste prevention and management. One such example is the Blue Lid Campaign that was initiated in Turkey in 2010 by the Faculty of Dentistry, Ege University 
and was later taken over by the Spinal Cord Paralytics Association of Turkey. The aim of the campaign was to collect large amounts of plastic lids, a valuable recyclable item, and exchange them for wheelchairs for people that could not afford them. Without any external funding, the project managed to engage the public at large and collect over 500 tonnes of plastic lids, providing 2000 wheelchairs to disabled people. Considering that bottle caps are one of the types of litter most frequently found on European beaches (Acoleyen et al., 2013), this initiative collected and promoted the recycling.

Such actions are very encouraging and show that the general public is not a passive receiver of information but can be an active player and a key part of the solution for marine litter prevention. This is also supported by the fact that most of the recorded practices (46\%) were initiated by non-governmental organisations and civil society and a significant portion of practices (14\%) were initiated by private entities (Orthodoxou et al., 2013). The success and expansion of such initiatives show that increasingly people become aware of the problem and take action to solve it.

An analysis of the recorded policy or regulation related initiatives indicates that if they are properly implemented and reinforced, they can be very successful tools for the reduction of marine litter, particularly if they focus on prevention. Policies alone are not, however, enough to raise awareness, deepen the understanding about the problem or emphasize the need to take action to a wider audience. Therefore, regulatory instruments must be complemented by initiatives that have an awareness-raising character. Measures should take a well-rounded, integrated and holistic approach to the issue of marine litter, one that includes a range of activities, covers a variety of themes and involves a range of different actors.

A more detailed evaluation of these practices by a panel of stakeholders (see further details on the evaluation methodology and discussion of results in Loizidou et al., 2014) favored preventive measures over mitigating actions, as well as practices with a proven track record and those that took an integrated approach to solving the marine litter problem. The experts also showed a preference for practices that have a high degree of social responsibility and practices that involve the public and promote active citizenship. Practices that are supported by a local administration were also preferred, as they were considered more sustainable.

MARLISCO recorded a relatively small number of the many practices that are being implemented around Europe. Although these may not be fully representative of all the different types of efforts in place, they show that a plethora of actions are taken by a variety of stakeholders. The MARLISCO database can thus serve as a starting point, a learning platform and a source of inspiration for anyone wishing to take action against this important 
environmental, economic and social problem. Complementing the web-based database, a Guide for Reducing Marine Litter (Orthodoxou et al., 2014), available in 6 languages, provides additional information on how to turn these practices into action.

\subsection{Empowering society through national fora}

The main participatory activities of MARLISCO consisted in the development and implementation of National Marine Litter Forum events, to facilitate a structured dialogue between the key stakeholders, relevant experts and the general public on the topic of 'marine litter: developing solutions together'. These events had the objective to provide the participants with the necessary scientific information in a readily accessible format and not only provide an opportunity for participants to actively engage in discussion but offering a platform for participants to submit viable solutions that may contribute to reducing marine litter in their countries.

A common format for the National events was designed, trialled and successfully applied in 12 MARLISCO partner countries between April 2014 and April 2015. Marine litter is a cross sectoral issue and across Europe the MARLISCO fora engaged more than 1500 stakeholders representing multiple sectors such as research and education, non-governmental organisations, governmental organisations, maritime activities, local authorities, media and communications, tourism and recreation, waste management, plastics industry, retail and marketing (Kopke et al., 2015).

The MARLISCO Fora format was modelled on participatory methodology developed for the participatory events in the project MARGOV (Vasconcelos \& Caser, 2012), promoting large-scale public involvement. Key aspects of the MARLISCO fora included the use of a professional facilitator, a live webcast, a panel of experts, early and proactive stakeholder engagement for live audience as well as for online participants. The forum format went beyond the traditional type workshop scenario by using live webcast to not only include more stakeholders but also to provide access to and a voice for participants from remote locations, increasing the visibility of the event.

To allow accessible transfer of the latest scientific knowledge, the MARLISCO fora included interactive activities for participants (e.g. table quiz and hands-on activities). In addition, an animation "Sources and Impacts of Marine Litter" was specifically developed for all MARLISCO fora to facilitate knowledge transfer, again taking advantage of multi-media elements to communicate with the wide audience engaged.

Flexibility of the MARLISCO fora format allowed individual MARLISCO partners to modify the above outlined aspects to improve their event based on learning 
from previous events or to incorporate cultural and political characteristics that may be important to engage the stakeholders in certain countries. One innovative element of the MARLISCO fora is the use of 'venue teams' that are present at the event and remote 'satellite teams' composed of participants joining in via the interactive webcast. Using a consensus approach, which is linked to higher quality decisions and greater satisfaction within a group and in turn better acceptance of group decisions (De Dreu \& West, 2001; Yang, 2010), teams were asked to work together in their groups to come up with actions that may help to address the problem of marine litter in their respective countries. Using this approach the stakeholders brought their unique experience to the table and worked together, in order to develop actions that are agreeable to all. Finally, participants were asked to vote as individuals on which action they thought was the most 'effective measure' and which action was the 'most implementable'.

Across all twelve events the majority of submitted actions, suggestions and ideas relate to recognised concepts and approaches that address issues of waste and litter in general. A substantial part of these proposals link to a need of increasing education and awareness (29\%) and appropriate disposal of waste (14\%) but also the Reduce (19\%), Reuse (9\%), Recycle (10\%) and Redesign (7\%) concepts, with the remaining ideas related to other type of approaches. This indicates that the overall strategies and concepts are well known but that more and definite measures and actions are required to utilise these established approaches and concepts to effectively address marine litter across Europe (Kopke et al., 2015).

Cross European analyses of submitted actions and measures (Kopke et al., 2015) showed that there is no one, specific action or suggestion to tackle the problem of marine litter, emphasising the need for wide ranging strategies. However, across events the importance of raising awareness and increasing education on the topic was highlighted as a common feature, indicating that participants felt there is a general lack of knowledge about marine litter, which is entirely in line with the key aim of the MARLISCO project. Moreover across Europe participants' perceptions analyses pre- and post-events indicated that the fora were viewed as a positive experience and that their views were heard and valued (Hartley et al., 2015a). Some statistically significant differences between pre- and post-fora responses, suggest that this form of stakeholder engagement works well, influencing participants views, increasing their sense of self-responsibility on the topic and the feasibility of solutions to address it. 


\subsection{Children as agents of change in society}

Children can be powerful agents of change in society, not only because they represent the next generation of consumers and decision-makers but often they can inspire and influence directly the behaviour of their families and even their close community (Vaughan et al., 2003). Educational activities about marine litter activities enhanced understanding and concern about the issue in UK school children (Hartley et al., 2015b) and thus have an important role to play. Recognising this, MARLISCO designed and launched a video competition in 14 countries (Fig. 1), as a specific strategy to engage youngsters, encouraging them to develop short videos on the topics of: - Where does marine litter come from and why is it a problem? - What can be done to help solve the problem? - What has been done in our school/local community to deal with this issue? This activity aimed at fostering a sense of citizenship in the younger generation, giving them an active voice in such societal problem and showing this is a global issue. On the other hand, the videos would have the potential to serve as messages that could be used to inform and trigger awareness in a wider audience.

The MARLISCO video contest targeted formal and informal groups of students, mainly between 12 and 18 years old. A common framework of timing and conditions was defined for all participating countries but implemented at the national level by MARLISCO partners. MARLISCO provided professional technical support on video production (e.g. workshops) to a limited number of school teams in every country. This helped to address potential capacity gaps and brought an added-value for teachers to embrace the initiative, as schools receive multiple invitations for external projects every year. In order to engage the wider public and foster the dissemination of the submitted videos, a stage of "public voting" was incorporated in the selection procedure and the public preferences were taken into account during the evaluation by a national jury.

Across the 14 participating countries, 379 videos were submitted, reflecting a total of 2123 youngsters between 7 and 18 years old actively involved in the making of these films. The dissemination of the candidate videos in social networks during the "public-voting" period led to a wide outreach, with some of the videos reaching 1.000 views during the first week. Close to the conclusion of the project (May 2015) the winning videos had received a total of 33.500 views on Youtube, had been screened at 6 European events and over 30 national ones, including most of the MARLISCO National Fora and at some of the venues of the MARLISCO exhibition.

A final multimedia product was developed featuring the winning video from all 14 participating countries, with English subtitles. A "teaser" showcasing the work of the youngsters was premiered during the plenary session of the 7th European Maritime Day Conference (19th May 2015, Bremen, Germany), with over 1300 participants registered. MARLISCO organised a 2-day joint, intercultural and 
facilitated programme in Bremen, which gathered 80 representatives from the winning teams and included a public recognition during the Conference.

Participation in the Video Contest resulted in an improved knowledge about marine litter, including the youngsters' understanding of the various causes and negative impacts but also an increase in the frequency of practical actions they reported to help prevent it (Hartley et al., 2015a; under review).

\subsection{Awareness raising and educational tools for informed decisions and responsible behaviour}

Enhanced awareness and deepened understanding of the issue of marine litter are crucial for catalysing change in the perceptions and attitudes of the different stakeholder groups, including the wider public, towards more informed decisions and responsible individual behaviour. In this context, MARLISCO developed a diversified set of awareness raising activities and educational tools, specifically an educational pack translated (Alampei et al., 2014) in more than 14 languages, including Arabic, and a corresponding e-learning course targeted to educators on how to apply it; a travelling exhibition that has been displayed in over 80 locations throughout Europe (www.marlisco.eu/exhibition-journeymap.en.html); documents highlighting the role of specific stakeholder groups and possibly their scope of action within their respective sector (Vlachogianni et al., 2015; Orthodoxou et al., 2014); a web-documentary; and a 'serious game' for youngsters.

The methodological approach deployed towards developing effective awareness raising and educational tools was based on the following considerations related to the information provided: that it is accurate based on sound scientific evidence, easy to access and easy to understand; that it is relevant and interesting to the intended audience; that it is delivered through appropriate channels; that it is tailored where necessary in language, style and content and it directs target audiences to where they can access further information if required. The MARLISCO guide on 'How to communicate with stakeholders about marine litter' (Hartley et al., 2015c) summarises insights about influencing change in attitudes and behaviour and guided the elaboration process of the aforementioned tools, including: the provision of a sense of ownership and collective action to the target audiences; showcases of feasible immediate actions and solutions to the issue of marine litter, while keeping in mind a longer term engagement in action; framing the problem as a current one, not just a future one and overall having a solution- and action-oriented approach. 
Among the key challenges of this cluster of activities has been the 'selection' and 'transformation' of the current state-of-the-art knowledge into relevant and informative but also motivating and engaging awareness raising and educational tools. Furthermore, given the broad geographic project outreach, the different national and regional specificities and context had to be taken into account, while articulating efforts within the diverse and multidisciplinary group of people in the MARLISCO partnership. The latter was particularly taken into account during the development of the educational pack in order also to accommodate the needs of the teachers in the various European countries.

Insights on the impact of a few of the aforementioned outreach and educational tools are described by Hartley et al (2015a). For example, short surveys conducted among visitors of the exhibition indicated not only a high concern about the issue but also an intention to be actively part of the solution, based on the subscription to a series of pledges to take action, namely separation of litter for recycling and the reduction of use of packaging. Regarding the online training course to educators, participants reported built confidence and ability to teach marine litter and increased their intent to integrate the subject, including the use the educational pack, in their teaching practice.

\section{Conclusions}

MARLISCO was set up to help understand and address some of the barriers that seemed to hinder an effective response from society on the issue of marine litter. Results from the stakeholder survey indicate the high level of concern from society but also the need for improved awareness and information. Evaluation of the different activities in terms of their impact on participants' perceptions and knowledge suggests that they can be effective in increasing the sense of individual responsibility for the problem but also the level of commitment in being an active part of the solution. Although awareness raising activities can be cost-effective they do not necessarily lead to changes in behaviour and is therefore important to make use of different approaches and evaluate these activities and tools systematically to better understand their potential benefits.

Marine litter is an example of a problem that does not have a "one solution fits all". It requires a combination of approaches, along the entire chain of products, rather than just focusing on "end-of-pipe" measures. It is therefore essential that different actors take their share of responsibility, instead of placing it elsewhere. Several examples of policies and initiatives exist that can be very successful tools for the reduction of marine litter, particularly if they focus on prevention. Prevention approaches were not only favoured during the evaluation of collected practices but seem to be broadly supported by stakeholders and the public, as over $35 \%$ of the proposed actions to address marine litter put forward 
during the national fora relate directly to the concepts of Reduce, Reuse and Redesign.

Given the participatory scope of this project, which required not only a mapping of stakeholders but recurring direct contact with key individuals and organisations, a diverse network across society was built in the different countries, around the topic of marine litter. In some countries, the engagement and participation of stakeholders was already in motion and with specific agendas in respect to the implementation of the MSFD. In such cases MARLISCO fed into and strengthened the ongoing processes. In other countries, the MARLISCO forum, for example, was among the first, consistent efforts to initiate a structured dialogue between key actors and open to civil society. In some cases, the established networks and positive experiences have supported the emerging of formal or informal national working groups, as the Marine Litter Portuguese Association (http://www.aplixomarinho.org/).

A very interesting aspect of this project was the diversity and dynamics within the partnership to develop and implement the activities in its different stages and places. A recognised factor of success was the personal dedication and commitment of specific individuals and organisations to the topic and the objectives set by the project. Additionally, it is important to highlight the mutual learning process not only within the consortium but also between the partners and the stakeholders. In a project of this nature and with such a multidisciplinary partnership, the interface and interaction between different areas of expertise (in this case natural and social sciences but also communication and multimedia) should not be underestimated. Enough resources and possibly a task-force with individuals that are able to bridge-in these different areas should be dedicated from the on-set of any cross-cutting project (further discussion in Vlachogianni et al, in preparation).

It may not be possible to assess the full outreach and impact of MARLISCO but it is plausible that its potential multiplier-effect reached far beyond the people that were directly involved in its different components. In any case, the overall levels of engagement have been outstanding, while the momentum resulting from the simultaneous and coordinated implementation of awareness activities in most of the European coastal countries has strengthened the current political impetus. MARLISCO leaves behind a valuable legacy of educational and guidance resources (see www.marlisco.eu) but also practical collaborative experiences and an increased sense of responsibility among stakeholders, which can be further built upon. It is therefore essential to find mechanisms that ensure continuity of the initiated processes and full exploitation of these materials.

Considering potential solutions to reduce marine litter provides an excellent opportunity to examine the consequences of societal, sectoral and personal 
decisions, and explore and promote the ethos of sustainable development. In other words marine litter can be used as a vehicle to inspire and promote more sustainable economies and lifestyles.

\section{Acknowledgements}

MARLISCO is a collective effort of a considerable number of dedicated people, across several countries in Europe. The national activities have been implemented by several organisations and their committed staff, and the authors would like to acknowledge, in particular:

Province of Teramo (Italy) - Doriana Calilli, Mara di Berardo and Luigi Alcaro

Coastal \& Marine Union - EUCC (Netherlands) - Lotte Kauffman, Maria Ferreira, Joos Versfelt and Erik Devilee

CEFAS (UK) - Eva Garnacho and Peter Kershaw

MerTerre (France) - Isabelle Poitou and Claire Poulin

RRC Koper (Slovenia) - Slavko Mezek, Tamara Ristic and Andreja Dujc,

UCC (Ireland) - Ashley Bennison, Jeremy Gault, Dee McElligott and Damien Haberlin

Mare Nostrum (Romania) - Andreea lonascu and Anca Gheorghe,

Küsten Union (Germany) - Matthias Mossbauer, Anke Vorlauf and Kristine Klesse

UBBSLA (Bulgaria) - Mariana Kancheva and Polina Antonova

PlasticsEurope (Spain) - Lola Ruiz and Ralph Schneider

FFCT-UNL (Portugal) - Flávia Silva, Lia Vasconcelos, Paula Sobral and Isabel Palma

MIO-ECSDE (Greece) - Vicky Malotidi, Michael Scoullos, Vasilis Psallidas and Anastasia Roniotes

TUDAV (Turkey) - Songül Yavuz, Ayaka Ozturk and Ozgegul Ozturk

KIMO (Denmark) - Ryan Metcalf

Last but not least, we thank the teams from Honkytonk and Mediatools, MARLISCO partners responsible for the delivery of some of the multimedia products, and Jane Lee for the animation work in the short video "Sources and Impacts of Marine Litter".

MARLISCO has received funding from the European Union's Seventh Framework Programme for Research \& Technological Development and Demonstration under grant agreement no 289042. The views and opinions expressed in this 
publication reflect the authors' view and the European Union is not liable for any use that may be made of the information contained therein.

\section{References}

Acoleyen, M., Laureysens, I., Lambert, S., Raport, L., van Sluis, C., Kater, B., van Onselen, E., Veiga, J. and Ferreira, M., 2013. Marine litter study to support the establishment of an initial quantitative headline reduction target. Final report SFRA0025. 315 pp. Available from: http://ec.europa.eu/environment/marine/good-environmentalstatus/descriptor-10/pdf/final_report.pdf

Alampei, I., Malotidi, V., Vlachogianni, T. and Scoullos, M. 2014. Know, Feel, Act! to Stop Marine Litter: Lesson plans and activities for middle school learners. MIO-ECSDE, 82pp.

Barnes, D. K. A., Galgani, F., Thompson, R. C. and Barlaz, M., 2009. Accumulation and fragmentation of plastic debris in global environments. Philosophical Transactions of the Royal Society B, 1985-1998. (doi:10.1098/rstb.2008.0205)

Braungart, M. and McDonough, W., 2002. Cradle to Cradle. Remaking the Way We Make Things. North Point Press, New York. 193 pp.

Browne, M., Chapman, M., Thompson, R., Zettler, L., Jambeck, J. and Mallos, N., 2015. Spatial and temporal patterns of stranded intertidal marine debris: is there a picture of global change? Environmental Science \& Technology, 49: 70827094. (doi: 10.1021/es5060572)

CBD - Secretariat of the Convention on Biological Diversity and the Scientific and Technical Advisory Panel-GEF., 2012. Impacts of Marine Debris on Biodiversity: Current Status and Potential Solutions, Montreal, Technical Series No. 67, 61 p.

Convery, F., McDonnell, S. and Ferreira, F., 2007. The most popular tax in Europe? Lessons from the Irish plastic bags levy. Environmental and Resource Economics, 38: 1-11.

De Dreu, C.K. and West, M., 2001. Minority dissent and team innovation: the importance of participation in decision making. Journal of Applied Psychology 86: 1191-1201.

European Commission, 2014. Towards a circular economy: a zero waste programme for Europe. Communication from the Commission to the European Parliament, the Council, the European Economic and Social Committee and the Committee of the Regions. Available from: 
http://ec.europa.eu/environment/circular-economy/pdf/circular-economycommunication.pdf

Eriksen, M., Lebreton, L., Carson, H., Thiel, M., Moore, C., Borerro, J., Galgani, F., Ryan, P. and Reisser, J., 2014. Plastic Pollution in the World's Oceans: More than 5 Trillion Plastic Pieces Weighing over 250,000 Tons Afloat at Sea. PLoS ONE, 12 : e111913 (doi: 10.1371/journal.pone.0111913)

Galgani, F., Fleet, D., Van Franeker, J., Katsanevakis, S., Maes, T., Mouat, J., Oosterbaan, L., Poitou, I., Hanke, G., Thompson, R., Amato, E., Birkun, A. and Janssen, C., 2010. Marine Strategy Framework Directive, Task Group 10 Report: Marine Litter. In JRC Scientific and Technical Reports (ed. N. Zampoukas). Ispra: European Commission Joint Research Centre. 50 pp.

Galgani, F., Hanke, G., Werner, S., Oosterbaan, L., Nilsson, P., Fleet, D., Kinsey, S., Thompson, R.C., van Franeker, J., Vlachogianni, T., Scoullos, M., Veiga J. M., Palatinus, A., Matiddi, M., Maes, T., Korpinen, S., Budziak, A., Leslie, H., Gago, J., Liebezeit, G., 2013. Guidance on Monitoring of Marine Litter in European Seas. EUR - Scientific and Technical Research series - ISSN 1831-9424 (online) edited by Hanke, G., Werner, S., Galgani, F., Veiga, J.M., Ferreira, M., 11/2013; Luxembourg: Publications Office of the European Union., ISBN: 978-92-7932709-4.

Galgani, F., Hanke, G. and Maes, T. 2015. Global Distribution, Composition and Abundance of Marine Litter. In: Bergmann, M., Gutow, L., Klages, M. (Eds.) Marine Anthropogenic Litter. Springer. 29-56p

Hartley, B. L., Pahl, S., and Thompson, R. T., 2013. Baseline Evaluation of stakeholder perceptions and attitudes towards issues surrounding marine litter. Deliverable D2.1 report. MARLISCO project. Marine Litter in European Seas: Social Awareness and Co-Responsibility. (EC FP7 Coordinated and Support Action, SIS-MML-289042).

Hartley, B. L., Holland, M., Pahl, S., and Thompson, R. C. 2015a. Evaluation of specific educational and outreach activities related to marine litter. Deliverable D2.5 report. MARLISCO project. Marine Litter in European Seas: Social Awareness and Co-Responsibility (EC FP7 Coordinated and Support Action, SISMML- 289042).

Hartley, B. L., Thompson, R. C. and Pahl, S. 2015b. Marine litter education boosts children's understanding and self-reported action. Marine Pollution Bulletin, 90: 209-217.

Hartley, B. L., Holland, M., Pahl, S., Thompson and R. C., 2015c. How to Communicate with Stakeholders about Marine Litter - A Short Guide to Influencing Behavioural Change. UK: Plymouth University Press. 
Hartley, B. L, Holland, M., Pahl, S., Alampei, I., Veiga, J. M. and Thompson. R. C. (under review). Turning the tide on trash: Empowering European educators and students to tackle marine litter.

HELCOM, 2009. Marine Litter in the Baltic Sea Region: Assessment and priorities for response. Helsinki, Finland, $20 \mathrm{pp}$

Kershaw, P., Katsuhiko, S., Lee, S., Leemseth, J. and Woodring, D., 2011. Plastic debris in the ocean, UNEP year book: emerging issues in our environment, $14 \mathrm{p}$.

Kershaw, P., Hartley, B., Garnacho, E. and Thompson, R., 2013a. Review of the current state of understanding of the distribution, quantities and types of marine litter. Deliverable D1.1 report. MARLISCO project. MARine Litter in Europe Seas: Social AwarenesS and CO-Responsibility (EC FP7 Coordinated and support action, SIS-MML-289042).

Kershaw, P.J., Alcaro, L., Garnacho, E., Doyle, T., Maes, T. and Painting, S., 2013b. Review of existing policies that may be applied to mitigate the impact of marine litter. Deliverable report D1.3. MARLISCO project. MARine Litter in Europe Seas: Social AwarenesS and CO-Responsibility (EC FP7 Coordinated and support action, SIS-MML-289042).

Kopke, K., Bennsion, A., Maes, T., Vlachogianni, T., Metcalfe, R. and Gheorge, A., 2015. MARLISCO Marine Litter Fora - outcomes for each of the twelve national events and for all regional seas. Deliverable D 4.3 report. MARLISCO project. Marine Litter in European Seas: Social Awareness and Co-Responsibility (EC FP7 Coordinated and Support Action, SIS-MML-289042).

Loizidou, X., Loizides, M. and Orthodoxou, D., 2014. A novel best practices approach: The MARLISCO case. Marine Pollution Bulletin, 88: 118-128.

Mouat, T., Lopez-Lozano, R. Bateson, H., 2010. Economic impacts of Marine litter. KIMO (Kommunenes Internasjonale Miljøorganisasjon), 117 pp.

Naustdalslid, J., 2011. Climate change: the challenge of translating scientific knowledge into action. International Journal of Sustainable Development \& World Ecology, 18: 243-252.

Oehlmann, J., Schulte-Oehlmann, U., Kloas, W., Jagnytsch, O., Lutz, I., Kusk, K. O., Wollenberger, L., Santos, E. M., Paull, G. C., Van Look, K. J. W. and Tyler, C. R., 2009. A critical analysis of the biological impacts of plasticizers on wildlife. Philosophical Transactions of the Royal Society 364: 2047-2062

OSPAR Commission, 2007. Monitoring of marine litter on beaches in the OSPAR region, Biodiversity Series, SBN 978-1-905859-45-0, 75 pp.

Orthodoxou D., Loizidou, X. and Loizides, M., 2013. Analysis of the processes and solutions of the 72 best practice examples. Deliverable D2.3 Report. 
MARLISCO project. MARine Litter in Europe Seas: Social AwarenesS and COResponsibility (EC FP7 Coordinated and support action, SIS-MML-289042).

Orthodoxou D., Loizidou, X. and Loizides, M. 2014. The MARLISCO Guide for Reducing Marine Litter: Get Inspired and Become Innovative Through Best Practices. Deliverable D2.4 Report. MARLISCO project. MARine Litter in Europe Seas: Social AwarenesS and CO-Responsibility (EC FP7 Coordinated and support action, SIS-MML-289042).

Poortinga, W., Whitmarsh, L. and Suffolk, C., 2013. The introduction of a singleuse carrier bag charge in Wales: Attitude change and behavioural spillover effects. Journal of Environmental Psychology, 36: 240-247.

Rochman, C. M. and Browne, M. A., 2013. Classify plastic waste as hazardous. Nature, 494: 169-171.

STAP - Scientific and Technical Advisory Panel, 2011. Marine Debris as a Global Environmental Problem: Introducing solutions based framework focused on plastic, A STAP Information Document, Global Environment Facility, Washington, DC. $40 \mathrm{pp}$

Teuten, E. L., Saquing, J. M., Knappe, D. R. U., Barlaz, M. A., Jonsson, S., Björn, A., Rowland, S. J., Thompson, R. C., Galloway, T. S., Yamashita, R., Ochi, D., Watanuki, Y., Moore, C., Viet, P., Tana, T. S., Prudente, M., Boonyatumanond, R., Zakaria, M. P., Akkhavong, K., Ogata, Y., Hirai, H., Iwasa, S., Mizukawa, K., Hagino , Y., Imamura, A., Saha, M. and Takada, S., 2009. Transport and release of chemicals from plastics to the environment and to wildlife. Philosophical Transactions of the Royal Society B, 364: 2027-2045.

Thompson, R. C., Moore, C., vom Saal, F. S., Swan, S. H., 2009. Plastics, the environment and human health: current consensus and future trends. Philosophical Transactions of the Royal Society B, 364: 2153-2166 (doi:10.1098/rstb.2009.0053)

UNEP, 2009 Marine Litter: A Global Challenge. Nairobi, 232 pp

UNEP/MAP MEDPOL, 2008. Results of the assessment of the status of marine litter in the Mediterranean. Athens, 89 pp.

UN - United Nations, 2012. Resolution adopted by the General Assembly on 27 July 2012, A/RES/66/288, 31 pp.

Vasconcelos, L. and Caser, U., 2012. MARGOV - building social sustainability. Journal of Coastal Conservation, 16: 523-530.

Vaughan, C., Gack, J., Solorazano, H., and Ray, R., 2003. The effect of environmental education on schoolchildren, their Parents, and community members: a study of intergenerational and intercommunity learning. The Journal of Environmental Education, 34: 12-21. 
Vlachogianni, T., Roniotes, A. and Veiga, J., MIO-ECSDE, 2015. Marine litter brochure sectors-specific 'Stopping marine litter together!'. Deliverable D6.4. MARLISCO project. Marine Litter in European Seas: Social Awareness and CoResponsibility (EC FP7 Coordinated and Support Action, SIS-MML-289042).

Vlachogianni, T., Veiga, J., Orthodoxou, D., Loizidou, X., Kopke, K., Hartley, B., Pahl, S., Thompson, R., Garnacho, E., Maes, T. and Roniotes, A. (in preparation). Understanding the science-society nexus through the marine litter challenge: lessons learned \& recommendations from the MARLISCO project.

Yang, M. C., 2010. Consensus and single leader decision-making in teams using structured design methods. Design Studies, 31: 345-362. 
Click here to download high resolution image

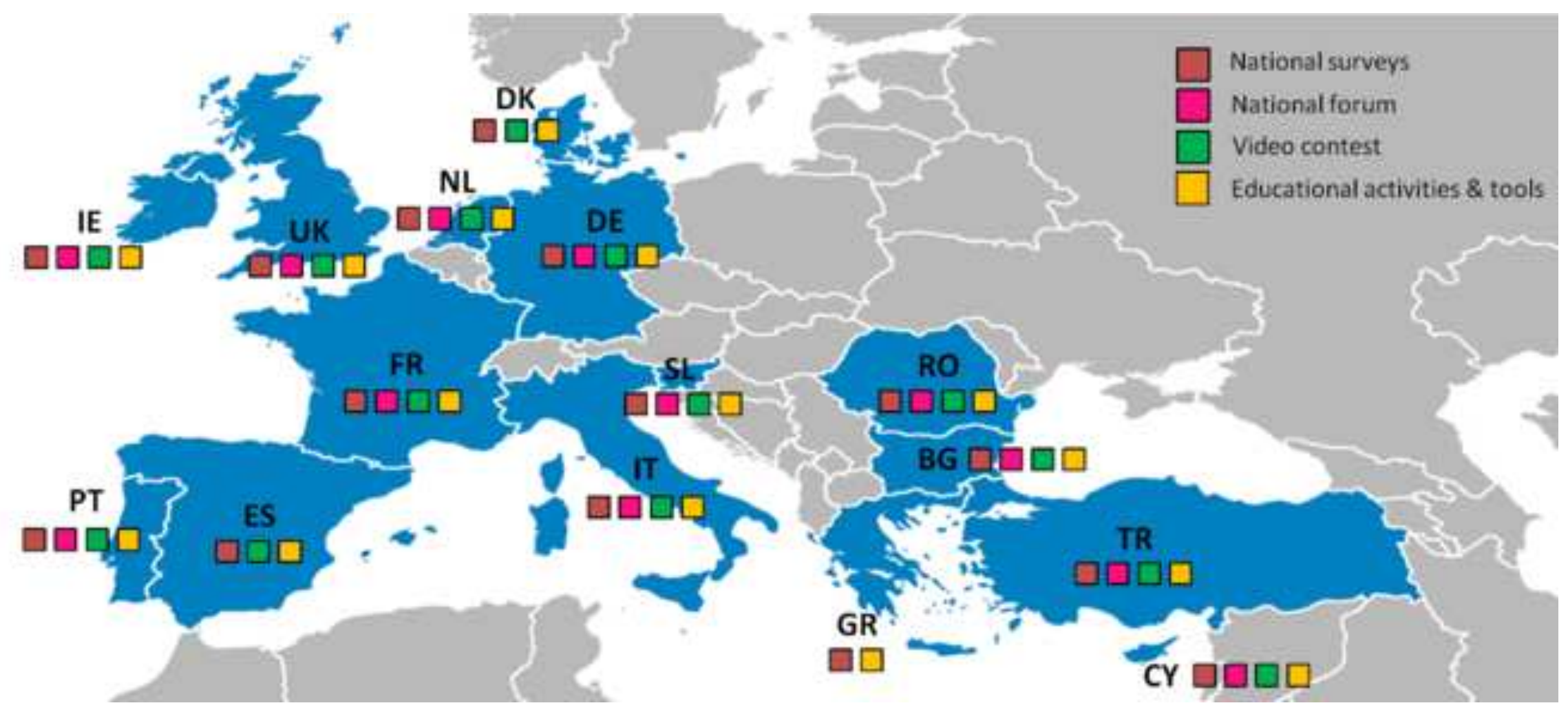

